\title{
Carbonic anhydrase IX in tumor tissue and sera of patients with primary cervical cancer
}

\author{
Linn Woelber ${ }^{1 *}$, Kerstin Kress ${ }^{1}$, Jan F Kersten ${ }^{2}$, Matthias Choschzick ${ }^{3}$, Ergin Kilic ${ }^{3}$, Uwe Herwig ${ }^{4}$, Christoph Lindner ${ }^{5}$, \\ Joerg Schwarz ${ }^{1,6}$, Fritz Jaenicke', Sven Mahner', Karin Milde-Langosch', Volkmar Mueller', Maike Ihnen ${ }^{1}$
}

\begin{abstract}
Background: Carbonic anhydrase IX (CAIX) is a membranous expressed metalloenzyme involved in pH homeostasis and cell adhesion. The protein is overexpressed in a variety of tumors and potentially associated with negative outcome. This study was designed to investigate the prognostic role of CAIX in serum and tumor tissue of patients with primary cervical cancer.
\end{abstract}

Methods: Tumor samples of 221 consecutive patients with primary cervical cancer who underwent surgery between 1993 and 2008 were analyzed for CAIX expression by immunohistochemistry. Additionally, preoperative serum CAIX concentrations were determined by ELISA in a subset of patients. Correlation with intratumoral CAIX expression as well as clinicopathological factors and outcome was analyzed.

Results: CAIX expression was observed in $81.9 \%$ of the tumor specimens; $62.0 \%$ showed a moderate or strong staining intensity. Moderate/strong expression was associated with squamous histology $(p=0.024)$, advanced tumor stage $(p=0.001)$, greater invasion depth $(p=0.025)$, undifferentiated tumor grade $(p<0.001)$ and high preoperative SCC-Ag values $(p=0.042)$. Furthermore patients with moderate/strong intratumoral CAIX expression had a higher number of metastatic lymph nodes compared to those with none/weak intratumoral expression levels ( $p=0.047$ ) and there was a non-significant association between high intratumoral CAIX expression and shorter survival $(p=0.118)$. Preoperative serum concentrations of CAIX ranged between 23 and $499 \mathrm{pg} / \mathrm{mL}$ and did not correlate with intratumoral expression or other clinicopathological variables.

Conclusion: CAIX is associated with advanced tumor stages and lymph node metastases in cervical cancer, potentially representing a new target in this disease. In contrast to other epithelial cancers we could not observe a correlation between serum CAIX and its intratumoral expression.

\section{Background}

Altered glycolysis is one of the crucial characteristics of cancer cells [1]. While normal cells can suppress the conversion of pyruvate to lactic acid in the presence of oxygen, cancer cells bypass oxidative phosphorylation in mitochondria for ATP production. The intracellular lactate excess results in acidification of the extracellular space and upregulation of acid-controlling proteins like carbonic anhydrases [2]. They catalyze the hydration of $\mathrm{CO}_{2}$ to $\mathrm{HCO}_{3}$ and play a central role in $\mathrm{pH}$ homeostasis $[3,4]$. Carbonic anhydrase IX (CAIX) is one of the members of this enzyme family; apart from its role in the $\mathrm{pH}$

\footnotetext{
* Correspondence: Iwoelber@uke.uni-hamburg.de

'Department of Gynecology and Gynecologic Oncology, University Medical Centre Hamburg-Eppendorf, Martinistrasse 52, 20246 Hamburg, Germany Full list of author information is available at the end of the article
}

regulation, CAIX has a function in cell adhesion and is important for growth and survival of tumor cells [5-7]. CAIX expression is induced by hypoxia through stabilization of the transcription factor HIF-1 $\alpha$ [8]. In normal tissue, expression of CAIX is very limited, low levels have been detected in gastric cells, the epithelium of the gall bladder, pancreatic ducts or in crypt cells of the small intestine [9]. Despite its sparse expression in normal tissue, CAIX is overexpressed in a variety of solid tumors [10]. High levels of CAIX were found to be associated with unfavourable patient outcome in several epithelial cancers [11-14]. In renal cell cancer, overexpression of CAIX is common and the possible role of CAIX targeting antibodies (WX-G250, Rencarex ${ }^{\circledR}$ ) is currently evaluated in phase III trials [15].

\section{Biomed Central}


Besides the cell-associated membranous form of CAIX, there is a soluble isoform that is released by proteolytic cleavage and can be detected in the serum [16]. This form of CAIX could serve as an easily accessible marker to stratify patients for therapy and monitor response. Information regarding the soluble form of CAIX is very limited [17]. There are studies on serum CAIX in renal cell cancer patients showing significantly higher concentrations in patients with metastatic disease than in patients with localized cancer $[16,18]$. Furthermore, renal cell cancer patients with high serum CAIX before surgery appear to be at significantly higher risk for disease recurrence than those with low preoperative values [18]. Other authors could show that CAIX was cleared from serum after complete tumor resection, suggesting a very promising marker to monitor therapy response and disease recurrence [16]. In vulvar cancer we could demonstrate similar results: Preoperative serum CAIX levels correlated with intratumoral CAIX expression and high values were prognostic for unfavourable outcome [19].

Cervical cancer is the third most common cause of cancer-related death in women accounting for approximately 500,000 new cases and 280,000 deaths worldwide each year [20]. Currently established prognostic factors include International Federation of Gynecology and Obstetrics (FIGO) stage, tumor volume, lymphatic spread, human papilloma virus (HPV) type 18 infection, invasion depths and vascular space invasion [21-23]. Although these prognostic factors are well established, the biological factors associated with recurrence and survival remain largely unknown and treatment options for recurrent or advanced disease are limited especially in patients already treated with radiochemotherapy. The identification of new prognostic factors and markers for therapy monitoring is therefore of high clinical relevance. In daily routine, serum Squamous Cell Cancer Antigen (SCC-Ag) is often used to monitor therapy of advanced disease [24]. Its value as a sensitive and specific tumor marker has been previously demonstrated [24-26]. The role of CAIX in cervical cancer has not been fully determined. Overexpression is potentially associated with a higher rate of lymph node metastases and with negative prognosis [27-29]. Serum CAIX could therefore be of clinical relevance for prognosis and therapy monitoring in cervical cancer. However, information on serum CAIX in cervical cancer is not available.

To gain insight into the role of intratumoral and serum CAIX in cervical cancer, we determined CAIX expression and its prognostic relevance in correlation with preoperative CAIX serum concentrations and other clinicopathological factors as well as survival in patients with primary cervical cancer.

\section{Methods}

\section{Patients}

Tumor tissue from 221 patients undergoing surgery for primary cervical cancer at 4 different institutions between 1993 and 2008 was analyzed. Detailed patient characteristics are listed in Table 1 . In addition, 46 preoperative serum samples from a subset of the included patients were analyzed. Serum samples were not routinely taken from all included patients before surgery but on a voluntary basis in one of the participating centers. To assure the analysis of a representative collective, FIGO stages were compared to those of the whole cohort showing a similar stage distribution (FIGO stage Ib1 52.2\%, Ib2 13.0\%, IIa 6.5\%, IIb $17.4 \%$, III 0.0\%, IVa $4.3 \%$, IVb $6.5 \%$, compare Table 1). Clinicopathologic factors were evaluated by reviewing medical charts and pathologic reports. For tumor staging, $6^{\text {th }}$ edition UICC TNM classification and stage groupings were used [30]. Informed consent for the scientific use of patient data, tumor tissue and serum had been obtained from all patients in coordination with the local ethics committee according to the principles of the declaration of Helsinki (Ethics committee of the Medical Board Hamburg, reference number \#190504). In the current study, all data were analyzed anonymously.

For 180 patients detailed therapy information and for 175 patients detailed follow-up data from the date of primary surgery to the date of death or last contact (July 2009) were available. The treatment of cervical cancer during the investigational period consisted of radical hysterectomy and resection of the pelvic and paraaortic lymph nodes via laparotomy for FIGO stages I and II. Only in stage Ia and Ib disease with fertility preserving objective radical hysterectomy was omitted. Adjuvant radio/chemotherapy of the pelvis and the paraaortic region was performed in case of advanced disease according to effective German Guidelines [31]. For FIGO stage III and IV cervical cancer primary radio/ chemotherapy was generally recommended. In our study, 24 patients were included with FIGO stage III/IV disease who received primary surgery. Those patients underwent surgery either to prevent further tumor invasion of the bladder and/or rectum or were not classified as FIGO III/IV until surgery (predominantly in case of paraaortic lymph node metastases).

\section{CAIX Immunohistochemistry}

To analyze the tissue-expression of CAIX, we performed immunohistochemistry (IHC) with paraffin embedded tumors from all included patients, using a commercially available CAIX IHC kit (Oncogene Science, Cambridge, Mass 0214, USA) according to the manufacturer's instructions. Tissue sections were cut at a thickness of 5 
Table 1 Patient characteristics $(n=221)$

\begin{tabular}{|c|c|c|}
\hline & & (\%) \\
\hline \multicolumn{3}{|l|}{ Age (years) } \\
\hline Median & 47 & \\
\hline Mean & 49 & \\
\hline Range & $23-85$ & \\
\hline \multicolumn{3}{|l|}{ Histological subtype $(n=221)$} \\
\hline Squamous cell carcinoma & 161 & $(72.9)$ \\
\hline Adenocarcinoma & 35 & $(15.8)$ \\
\hline Adenosquamous cell carcinoma & 25 & $(11.3)$ \\
\hline \multicolumn{3}{|l|}{ Tumor stage $(F I G O)(n=221)$} \\
\hline la1 & 0 & $(0.0)$ \\
\hline la2 & 3 & $(1.4)$ \\
\hline |b1 & 113 & $(51.1)$ \\
\hline lb2 & 20 & (9.0) \\
\hline Ila & 17 & $(7.7)$ \\
\hline Ilb & 44 & $(19.9)$ \\
\hline IIla & 0 & $(0.0)$ \\
\hline IIlb & 1 & $(0.5)$ \\
\hline IVa & 7 & $(3.2)$ \\
\hline $\mathrm{IVb}$ & 16 & $(7.2)$ \\
\hline \multicolumn{3}{|l|}{ Lymph node involvement $(n=221)$} \\
\hline NO & 168 & $(76.0)$ \\
\hline N1 & 53 & $(24.0)$ \\
\hline \multicolumn{3}{|l|}{ Removed lymph nodes $(n=221)$} \\
\hline Median & 27 & \\
\hline Mean & 30 & \\
\hline Range & $2-88$ & \\
\hline \multicolumn{3}{|l|}{ Affected lymph nodes $(n=53)$} \\
\hline Median & 2 & \\
\hline Mean & 3 & \\
\hline Range & $1-14$ & \\
\hline \multicolumn{3}{|l|}{ Distant metastasis $(n=181)$} \\
\hline MO & 165 & $(91.2)$ \\
\hline M1 & 16 & (8.8) \\
\hline \multicolumn{3}{|l|}{ Tumor grade $(n=215)$} \\
\hline G1 & 9 & $(4.2)$ \\
\hline G2 & 95 & $(44.2)$ \\
\hline G3 & 111 & $(51.6)$ \\
\hline \multicolumn{3}{|c|}{ Lymphovascular space invasion $(n=196)$} \\
\hline LO & 64 & $(32.7)$ \\
\hline L1 & 132 & $(67.3)$ \\
\hline \multicolumn{3}{|l|}{ Vascular invasion $(n=169)$} \\
\hline Vo & 151 & $(89.3)$ \\
\hline V1 & 18 & $(10.7)$ \\
\hline \multicolumn{3}{|l|}{ Surgical therapy $(n=181)$} \\
\hline Radical hysterectomy & 180 & $(99.5)$ \\
\hline Trachelectomy & 1 & $(0.5)$ \\
\hline \multicolumn{3}{|c|}{ Preoperative SCC serum concentration $(\mu \mathrm{g} / \mathrm{l})(n=144)$} \\
\hline Median value & 1.4 & \\
\hline Mean & 5.2 & \\
\hline Range & $0.2-107.0$ & \\
\hline
\end{tabular}

Table 1 Patient characteristics $(\mathbf{n}=\mathbf{2 2 1})$ (Continued)

\begin{tabular}{|c|c|c|}
\hline \multicolumn{3}{|l|}{ Adjuvant Therapy $(n=180)$} \\
\hline No therapy & 88 & $(48.9)$ \\
\hline Adjuvant radiotherapy & 44 & $(24.4)$ \\
\hline Adjuvant concomitant chemoradiotherapy & 48 & $(26,7)$ \\
\hline \multicolumn{3}{|l|}{ Follow-up (months) $(n=175)$} \\
\hline Median & 49 & \\
\hline Mean & 63 & \\
\hline Range & 2-193 & \\
\hline Disease free surviving & 131 & $(74.9)$ \\
\hline Disease recurrence & 44 & $(25.1)$ \\
\hline Died of disease & 38 & $(21.7)$ \\
\hline \multicolumn{3}{|l|}{ CAIX expression (IRS) $(n=221)$} \\
\hline Median expression & 2 & \\
\hline Mean & 3 & \\
\hline Range & $0-12$ & \\
\hline IRS 0 & 40 & 18.1 \\
\hline IRS 1 & 44 & 19.9 \\
\hline IRS 2 & 35 & 15.8 \\
\hline IRS 3 & 9 & 4.1 \\
\hline IRS 4 & 32 & 14.5 \\
\hline IRS 6 & 29 & 13.1 \\
\hline IRS 8 & 2 & 0.9 \\
\hline IRS 9 & 23 & 10.4 \\
\hline IRS 12 & 7 & 3.2 \\
\hline \multicolumn{3}{|l|}{ CAIX serum concentration $(\mathrm{pg} / \mathrm{mL})(n=46)$} \\
\hline Median concentration & 104 & \\
\hline Mean & 137 & \\
\hline Range & $23-499$ & \\
\hline
\end{tabular}

IRS: Immunoreactive score (IRS) according to W. Remmele and H. E. Stegner.

$\mu \mathrm{m}$ and mounted on slides (Superfrost/Plus, Sondheim Germany), dewaxed with Xylene and gradually hydrated. Afterwards a peroxidase blocking solution was applied and sections were incubated at room temperature for 5 minutes followed by several washings in phosphate buffered saline (PBS) (CA IX IHC Kit, Reagent H). Adjacent all sections were probed with the primary mouse anti-CA IX antibody (prediluted at $0.5 \mu \mathrm{g} / \mathrm{mL}$, CA IX IHC Kit, Reagent B) incubating them at room temperature for 30 minutes. After several washings in PBS, slides were covered with the biotinylated secondary antibody (CA IX IHC Kit, Reagent C) for 10 minutes, washed several times and incubated with HRP-labeled streptavidin (CA IX IHC Kit, Reagent D) for another 10 minutes to be washed three times again. Finally the DAB substrate-chromogen solution (CA IX IHC Kit, Reagent F1, F2 and F3) was applied for 5 minutes followed by washings in Aqua dest. The slides were briefly counterstained with haematoxylin (CA IX IHC Kit, Reagent G) and dehydrated before mounting.

The IHC staining was evaluated independently by two gynecopathologists using the immunoreactive 
score (IRS) according to W. Remmele and H. E. Stegner as product of staining intensity (graded 0-3) and percentage of positive cells (graded 0-4, 0: $0 \%, 1$ : $<10 \%, 2: 10-50 \%, 3: 51-80 \%, 4:>80 \%)$ resulting in a score from 0-12 [32].

\section{Quantitative analysis of serum CAIX level}

CAIX was quantified by a commercially available ELISA (Oncogene Science, Cambridge, Mass 0214, USA). Control samples consistent of purified CAIX protein in buffer with low, medium and high concentrations as included in the ELISA kit ("MN/CAIX ELISA controls"). Serum samples and controls were diluted 1:2 with sample diluting buffer (containing bovine serum albumin, mouse IgG, buffer salts and $0.09 \%$ sodiumazide). One hundred microliters of the standards, of diluted control samples and of diluted serum samples were dispensed into the wells of a 96-well plate (coated with the monoclonal capture antibody) and incubated for two hours at room temperature on a shaker at $800 \mathrm{rpm}$. Wells were washed, and $100 \mu \mathrm{l}$ of the detection antibody (containing biotinylated anti-CAIX antibody) was added. The plates were incubated for $30 \mathrm{~min}$ at room temperature, washed, and then further incubated with $100 \mu \mathrm{l}$ of a streptavidin-HRP (horseradish peroxidase) conjugate for $30 \mathrm{~min}$ at room temperature. After washing, $100 \mu \mathrm{l}$ of chromogenic substrate (TMB blue substrate) was added for $30 \mathrm{~min}$ at room temperature. The reaction was stopped with $100 \mu \mathrm{l}$ of $2.5 \mathrm{~N}$ sulphuric acid and absorbance was read at $450 \mathrm{~nm}$ by an automated plate reader (Tecan, Crailsheim, Germany). The CAIX concentration was estimated from the standard curve. Each sample, standard, and control was analyzed in duplicate.

\section{Statistics}

All statistical analyses were conducted using the $\mathrm{R}$ open source statistical software package [33]. p-values $<0.05$ were considered statistically significant. In accordance with previously published data on CAIX expression in epithelial tumors we analyzed CAIX expression in a two class system, merging IRS score 0 and 1 into one class corresponding with none/weak CAIX expression levels and IRS score 2 - 12 into another class corresponding with moderate/strong intratumoral CAIX expression $[19,34,35]$. Mann-Whitney-U-Tests and Fisher's exact tests were used to calculate correlations between CAIX expression, serum CAIX and clinicopathological parameters. Kaplan-Meier analyses of overall and diseasefree survival were performed. The log rank test was applied to examine the relationship between serum CAIX, intratumoral CAIX expression and survival. Additionally, we performed a stratified log rank test, comparing CAIX effects on survival in patients with FIGO stage I and FIGO stage II-IV disease, to investigate potential stage dependant differences. The Cox Proportional Hazard Model was used for multivariate analyses.

\section{Results \\ Patients}

A total of 221 patients were included in this study; detailed characteristics are listed in Table 1. For 180 patients detailed therapy information and for 175 patients detailed follow-up data were available. All patients underwent radical surgery. No further treatment was initiated in 88 patients $(48.9 \%)$, whereas 92 (51.1\%) patients received adjuvant radio- and/or chemotherapy. The predominantly applied chemotherapy regimen was cisplatin as a single agent, 4 patients received a cisplatin based combination therapy. Median follow-up time was 49 months. At the time of last follow-up, 131/175 (74.9\%) patients were alive and without relapse whereas 38/175 (21.7\%) patients had died from the disease. In case of disease recurrence $(n=44)$, relapse was locoregional in 10 patients, distant in 13 patients and both in 18 patients ( 3 cases unknown).

\section{CAIX immunohistochemistry}

A total of 221 tumor samples were stained for determination of CAIX expression. CAIX was detectable in 181 (81.9\%) of all specimens. 137 (62.0\%) samples exhibited a moderate or strong (score 2-12) staining result (Table 1). Figure 1 shows representative tumor samples with none/ weak/moderate/strong CAIX expression. CAIX protein expression was always membranous. Tumor associated stromal cells as well as inflammatory cells stained negative for CAIX. Table 2 summarizes the correlation of CAIX expression with clinicopathological parameters. Moderate/strong expression was associated with squamous histology $(\mathrm{p}=0.024)$, advanced FIGO and $\mathrm{pT}$ stage $(\mathrm{p}=0.013$ and $\mathrm{p}=0.001)$, greater invasion depth $(\mathrm{p}=0.025)$, undifferentiated tumor grade $(\mathrm{p}<0.001)$ and high preoperative SCC-Ag concentration ( $p=0.042)$. Furthermore, patients with moderate/strong intratumoral CAIX expression had a higher number of metastatic lymph nodes compared to those with none/weak intratumoral expression levels $(\mathrm{p}=0.047)$. Fifteen $(11.0 \%)$ of the patients with moderate/strong intratumoral CAIX expression showed three or more lymph node metastases whereas in only 2 cases $(2.4 \%)$ with none/weak CAIX expression three or more positive lymph nodes were diagnosed. We could not demonstrate an association between CAIX expression and lymphovascular space invasion or patients' age. There was an association between none/weak intratumoral CAIX expression and longer survival; however, this result failed to reach statistical significance (overall survival $\mathrm{p}=0.118$, Figure 2; disease-free survival $\mathrm{p}=0.220$, not shown). The potential 

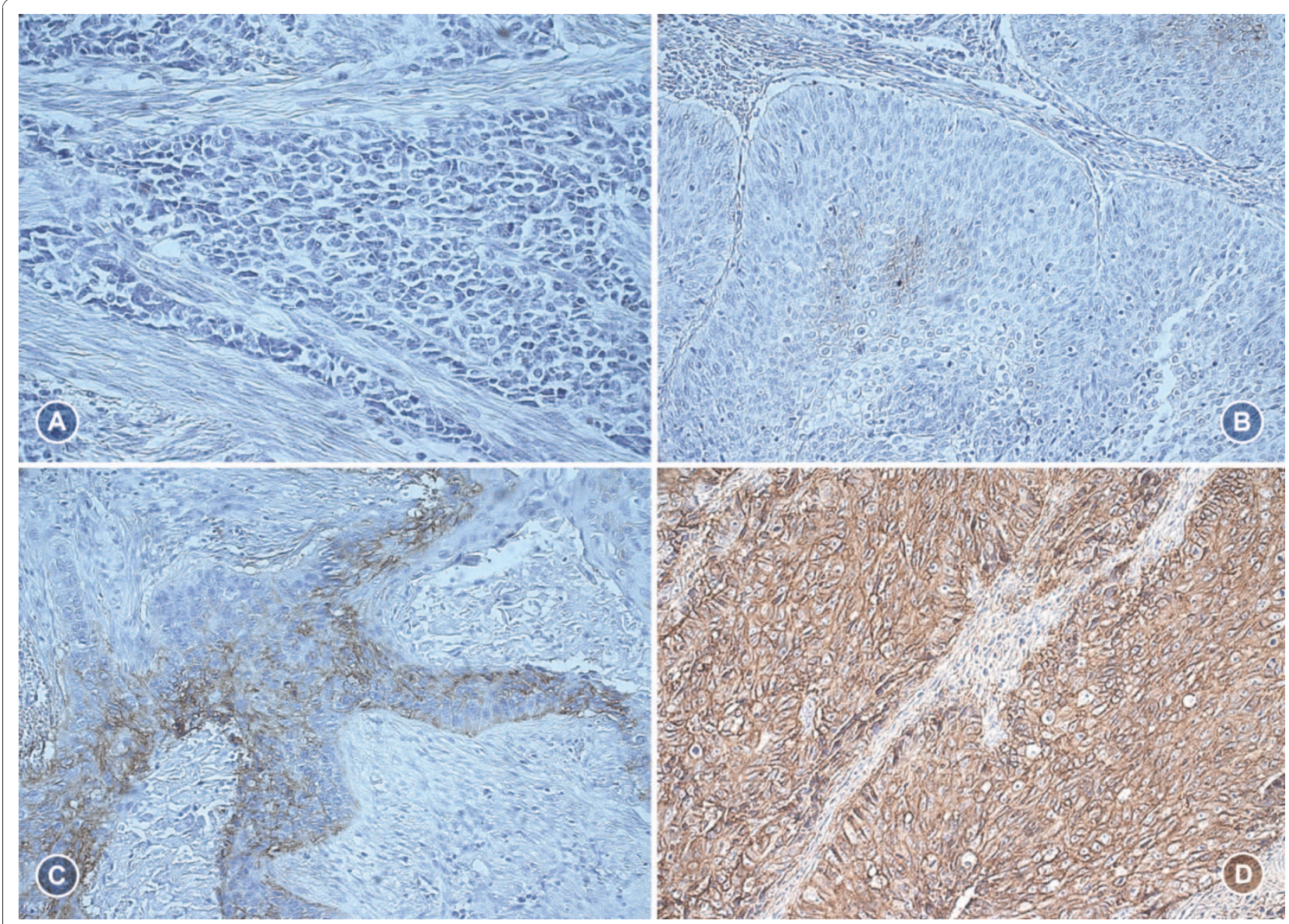

Figure 1 CAIX IHC: none (A, IRS 0), weak (B, IRS 1), moderate (C, IRS 4) and strong (D, IRS 12) expression.

negative effect of a moderate/strong intratumoral CAIX expression on survival did not significantly differ between FIGO stages I and II-IV in a stratified survival analysis (disease-free survival $\mathrm{p}=0.580$, overall survival $\mathrm{p}=$ 0.331 , not shown).

\section{Serum CAIX}

Median preoperative serum CAIX was $104 \mathrm{pg} / \mathrm{mL}$ (mean 137.0, range 23-499 pg/mL). Patients with a moderate/strong intratumoral CAIX expression did not show significantly higher serum concentrations (median 110 $\mathrm{pg} / \mathrm{mL}$, range $23-499 \mathrm{pg} / \mathrm{mL}$ ) compared to patients with none/weak expression (median $91 \mathrm{pg} / \mathrm{mL}$, range 27-257 $\mathrm{pg} / \mathrm{mL}, \mathrm{p}=0.466)$. Furthermore, serum CAIX did not show any association with the analyzed clinicopathological factors (tumor stage, lymph node involvement, lymphovascular space invasion, invasion depth, tumor grade, histological type, preoperative serum SCC-Ag). Nevertheless, there was a non-significant association between high preoperative serum CAIX and shorter disease-free survival (disease-free survival $\mathrm{p}=0.127$, Figure 3; overall survival $\mathrm{p}=0.320$, not shown). After stratifying for FIGO stages, the negative effect of a serum CAIX above median on survival was especially distinct in patients with FIGO stage I disease (diseasefree survival $\mathrm{p}=0.051$, Figure 4 ; overall survival $\mathrm{p}=$ 0.059 , not shown)

\section{Multivariate analysis}

The independent prognostic impact of intratumoral CAIX expression and preoperative serum CAIX for disease-free and overall survival adjusted for tumor stage (FIGO), pN, tumor grade and depth of invasion was analyzed using the Cox Proportional Hazard Model. Higher FIGO stage and nodal involvement were shown to be independent prognostic factors for decreased survival. Neither moderate/strong CAIX expression nor serum CAIX above median before surgery could be demonstrated independently relevant for prognosis in this patient cohort.

\section{Discussion}

In this study we analyzed the prognostic relevance of CAIX in tumor tissue of 221 and sera of 46 patients 
Table 2 Correlations between CAIX expression and clinicopathological factors

\begin{tabular}{|c|c|c|c|c|}
\hline & & \multicolumn{2}{|c|}{ Carbonic anhydrase IX expression } & \multirow[t]{2}{*}{$\mathrm{p}$-value } \\
\hline & & none/weak & moderate/strong & \\
\hline All samples $(n=221)$ & & 84 & 137 & \\
\hline \multirow[t]{3}{*}{ Histological subtype $(\mathrm{n}=221)$} & squamous & 53 & 108 & 0.024 \\
\hline & adenomatous & 20 & 15 & \\
\hline & adenosquamous & 11 & 14 & \\
\hline \multirow[t]{3}{*}{ FIGO stage $(n=221)$} & I & 62 & 74 & 0.013 \\
\hline & $\|$ & 15 & 46 & \\
\hline & III/IV & 7 & 17 & \\
\hline \multirow[t]{3}{*}{ UICC tumor stage $(n=221)$} & pT1 & 65 & 76 & 0.001 \\
\hline & pT2 & 15 & 55 & \\
\hline & $\mathrm{pT} 3 / 4$ & 4 & 6 & \\
\hline \multirow[t]{2}{*}{ Nodal involvement $(n=221)$} & $\mathrm{pNO}$ & 69 & 99 & 0.106 \\
\hline & $\mathrm{pN} 1$ & 15 & 38 & \\
\hline \multirow[t]{3}{*}{ Number of positive lymphnodes $(n=221)$} & 0 & 69 & 99 & 0.047 \\
\hline & $1-3$ & 13 & 23 & \\
\hline & $>3$ & 2 & 15 & \\
\hline \multirow[t]{3}{*}{ Tumor grade $(n=215)$} & G1 & 9 & 0 & $<0.001$ \\
\hline & G2 & 32 & 63 & \\
\hline & G3 & 39 & 72 & \\
\hline \multirow[t]{2}{*}{ Lymphovascular space invasion $(n=196)$} & LO & 25 & 39 & 0.875 \\
\hline & L1 & 49 & 83 & \\
\hline Invasion depth in $\mathrm{mm}(\mathrm{n}=185)^{*}$ & median & $12(n=70)$ & $16(n=115)$ & 0.025 \\
\hline Patients age in years $(n=221)^{*}$ & median & 49.5 & 47.0 & 0.549 \\
\hline SCC-Ag in $\mu g / L(n=144)^{*}$ & median & $1(n=55)$ & $1.9(n=89)$ & 0.042 \\
\hline Serum CAIX in $\mathrm{pg} / \mathrm{mL}(\mathrm{n}=46)^{*}$ & median & $91(n=17)$ & $110(n=29)$ & 0.466 \\
\hline
\end{tabular}

Fisher's exact test was used for categorical data, the Mann-Whitney-U-Test for continuous variables $\left(^{*}\right)$.

with primary cervical cancer, representing the largest study on CAIX expression in cervical cancer and the first study investigating the role of serum CAIX for this tumor entity. The high number of samples in combination with survival data enables a comprehensive survey of CAIX expression with respect to multiple clinicopathological parameters.

More than $80 \%$ of the patient samples stained positive for CAIX (62\% with moderate/strong intensity). This expression rate confirms previously published results: In a study by Loncaster et al, expression was found in $79 \%$ of the samples $[13,36]$. Tumor associated stromal cells as well as inflammatory cells stained negative for CAIX. In our analysis, moderate/strong intratumoral CAIX expression was significantly associated with advanced tumor stages, a higher depth of invasion, undifferentiated tumor grade as well as higher preoperative serum SCC levels. Furthermore, there was a strong correlation of CAIX expression to the number of positive locoregional lymph nodes. All of these features are well known to be associated with unfavorable clinical outcome [21,22]. These results are confirmed by published results from smaller studies on CAIX expression in cervical cancer [27-29]. Up-regulation of CAIX is probably an adaptation to aerobic glycolysis in tumor cells for maintenance of the intracellular $\mathrm{pH}$ in advanced carcinomas. Acidification of extracellular space by this mechanism may contribute to tumor cell invasion and development of metastases $[37,38]$. High levels of CAIX may therefore promote the development of locoregional lymph node metastases. In our study we also found an association between moderate/strong intratumoral CAIX expression and shorter survival. The effect was not significant, possibly because of a restricted number of patients with advanced tumor stages and/or positive lymph nodes. Taken together, enhanced expression of CAIX appears to be an important feature of cancerogenesis in cervical cancer.

Serum CAIX could therefore serve as an easily accessible marker to stratify patients for therapy and monitor response. While tumor tissue is usually only available at surgery, serum is easily accessible during the whole course of the disease. This is especially relevant in patients that are not always treated with a primarily 


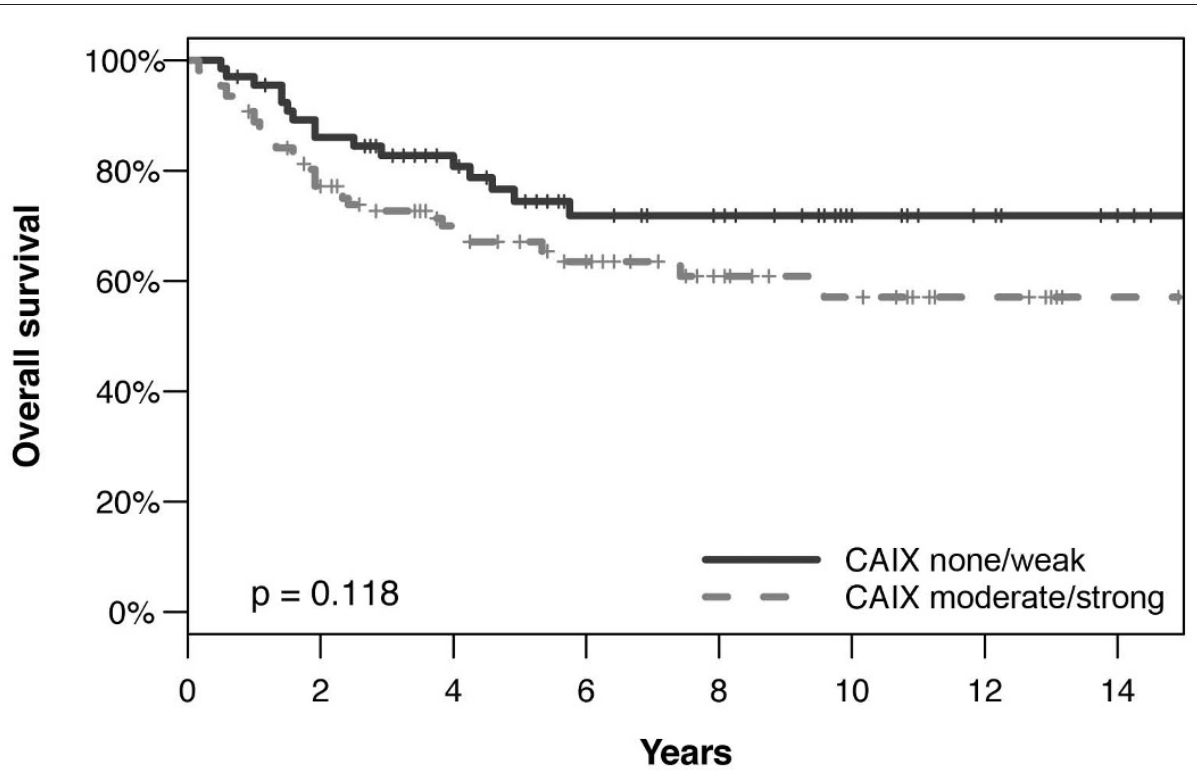

Events/patients under risk

$\begin{array}{lllllllll}\text { CAIX none/weak } & 0 / 67 & 9 / 54 & 3 / 42 & 4 / 28 & 0 / 23 & 0 / 14 & 0 / 9 & 0 / 6 \\ \text { CAIX moderate/strong } & 0 / 108 & 24 / 75 & 7 / 50 & 3 / 31 & 1 / 20 & 1 / 14 & 0 / 6 & 0 / 1\end{array}$

Figure 2 Overall survival of patients with moderate/strong versus vs. none/weak intratumoral CAIX expression $(p=0.118, n=175)$.

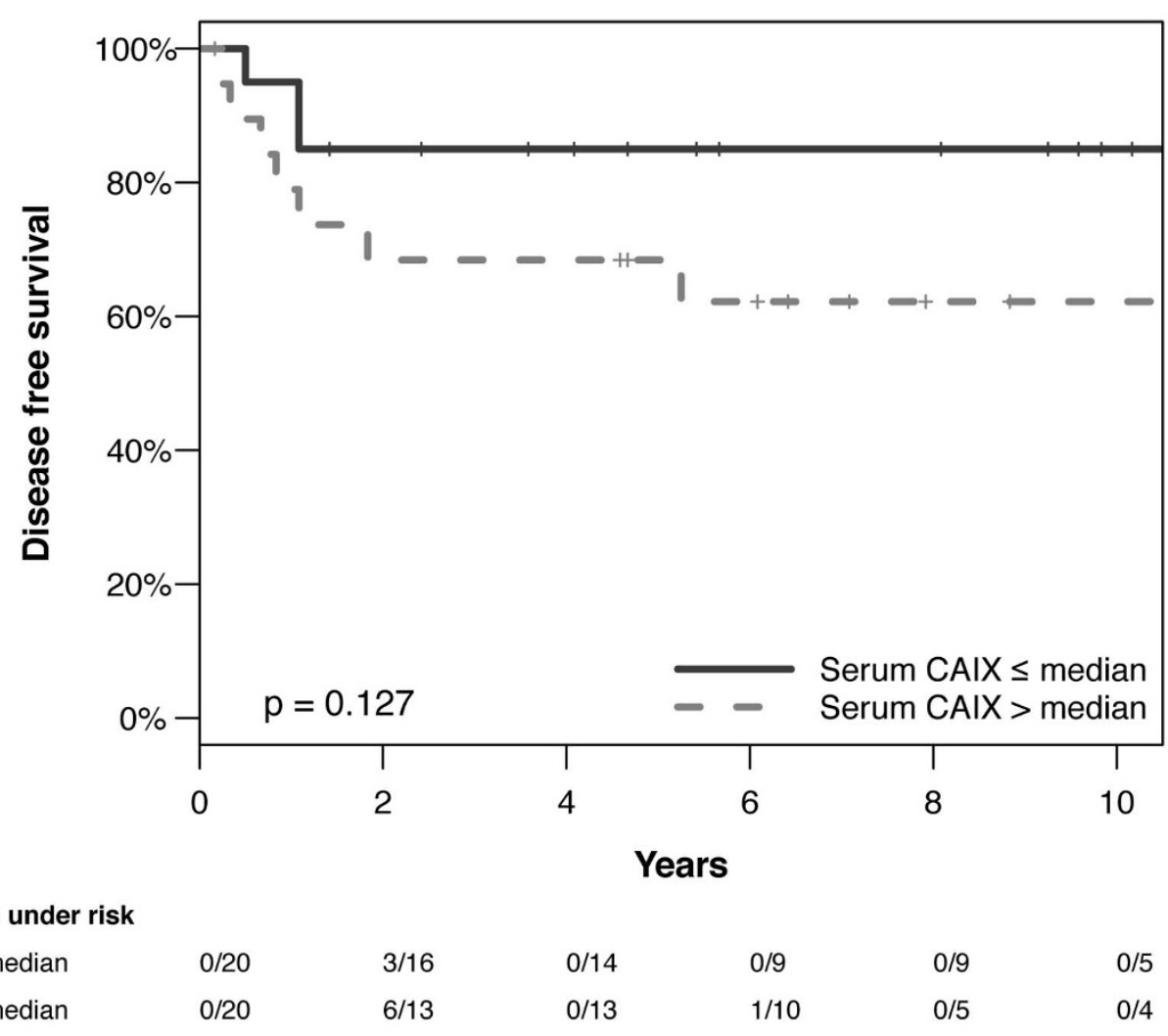

Figure 3 Disease-free survival of patients with Serum CAIX below and above the median of $104 \mathrm{pg} / \mathrm{ml}(\mathrm{p}=0.127, \mathrm{n}=40)$ 


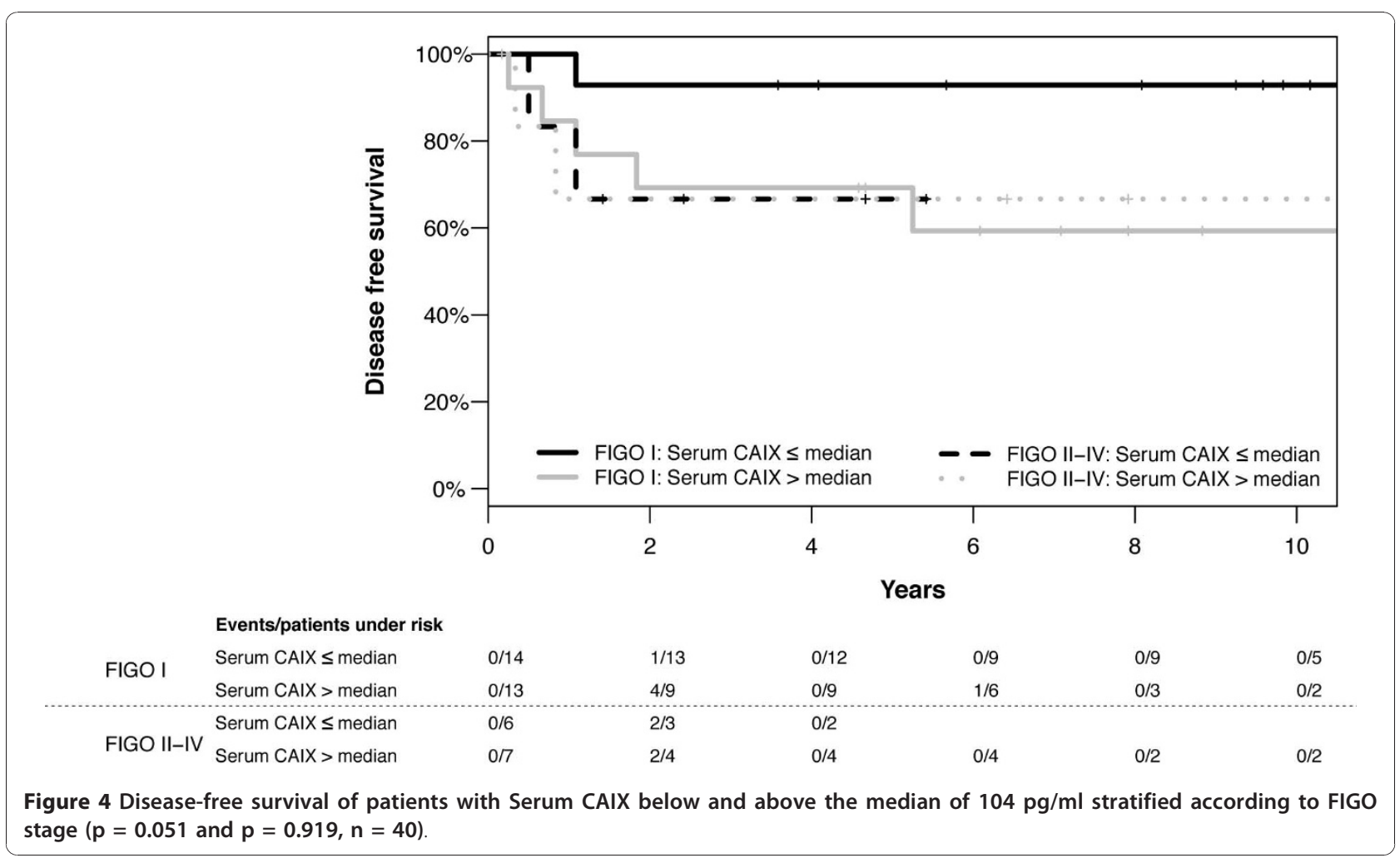

surgical approach, as for example in advanced cervical cancer. Currently, detailed information on serum CAIX as a biomarker is only available in renal cell cancer patients: Serum CAIX has been shown to serve as a promising marker for therapy monitoring and prediction of prognosis in patients with cancer of the kindney [16]. The marker is especially interesting as some groups have reported a clearance of CAIX from serum after complete tumor resection [16]. However, in a longitudinal study on serum CAIX in ovarian cancer patients at our institution, we could not observe a clearance of CAIX from serum after surgery and chemotherapy [17].

To investigate the role of serum CAIX in cervical cancer we determined preoperative serum concentrations in a subset of 46 patients. Patients in our study showed CAIX serum concentrations between 23 and $499 \mathrm{pg} / \mathrm{mL}$ with a mean of $137 \mathrm{pg} / \mathrm{mL}$. Patients with renal cell carcinoma had similar concentrations in localized disease though concentrations were measured using a different assay $(91.65 \pm 13.29 \mathrm{pg} / \mathrm{mL})$ [18]. In our own series on preoperative serum CAIX in vulvar cancer analyzed by the same assay, serum concentrations (range 56 and $879 \mathrm{pg} / \mathrm{mL}$, mean $237.29 \mathrm{pg} / \mathrm{mL}$ ) were above those found in the current study despite mostly locally restricted disease [19]. A defined cut-off level for normal values of serum CAIX has not been determined yet and conflicting results have been published concerning CAIX serum levels in healthy males and females. In the series of Li et al. mean serum CAIX level was significantly higher in renal cell cancer patients than in healthy individuals (patients with metastatic renal cell cancer: mean $216.68 \pm 67.02 \mathrm{pg} / \mathrm{mL}$; patients with localized disease: mean $91.65 \pm 13.29 \mathrm{pg} / \mathrm{mL}$ and healthy individuals: mean $14.59 \pm 6.22 \mathrm{pg} / \mathrm{mL}$ ). In contrast to these findings, others reported considerably higher levels in normal sera (mean $221 \mathrm{pg} / \mathrm{mL}$ in healthy females) [39].

Information regarding the relation of intratumoral CAIX expression and detection of its soluble isoform is very limited. A recently published study on CAIX expression and serum concentrations in renal cell cancer could not demonstrate a correlation: Zhou et al. found serum CAIX to be associated with tumor size but not with intratumoral CAIX expression [40]. Possibly, intratumoral hypoxia, increasing with tumor size, causes the soluble form of CAIX to be released into bloodstream. In contrast to these results, a study on urinary CAIX in renal cell cancer patients could demonstrate a coherence of soluble CAIX and intratumoral CAIX expression [41]. Both studies are based on small patient numbers. In our previous study on vulvar cancer, patients with high serum CAIX showed a significantly higher intratumoral expression of CAIX while the current study fails to proof this correlation for cervical cancer. One possible explanation could be the low proportion of patients with advanced disease. 
The prognostic role of the soluble form of CAIX in cancer patients is extremely limited. We observed a non-significant association between high CAIX serum concentrations before surgery and unfavourable diseasefree survival; this effect was especially seen in early stage disease. Our findings are consistent with results on CAIX serum concentrations in renal cell cancer: Li et al. could demonstrate a decreased disease-free survival for patients with high serum CAIX concentrations before surgery [18]. However, in our longitudinal study on serum CAIX in ovarian cancer patients, we could not observe a prognostic relevance of preoperative serum CAIX for survival [17].

\section{Conclusions}

CAIX overexpression is seen in a great proportion of patients with cervical carcinoma and related to adverse clinicopathological parameters as well as unfavorable outcome. The exclusive expression of CAIX in cancer tissue qualifies this protein as suitable target for therapeutic interventions. The role of serum CAIX in this context remains uncertain; a detailed evaluation of this serum marker in greater cohorts is highly desirable to clarify its clinical role.

\author{
Acknowledgements \\ We thank Katrin Beck for excellent technical assistance as well as Walter \\ Carney and Peter Hamer for their continuous support. \\ This study was funded by internal departmental sources. CAIX \\ immunohistochemistry and ELISA kits were provided at no cost by \\ Oncogene Science (Cambridge, Mass 0214, USA).
}

\section{Author details \\ 'Department of Gynecology and Gynecologic Oncology, University Medical Centre Hamburg-Eppendorf, Martinistrasse 52, 20246 Hamburg, Germany. ${ }^{2}$ Department of Medical Biometry and Epidemiology, University Medical Centre Hamburg-Eppendorf, Martinistrasse 52, 20246 Hamburg, Germany. ${ }^{3}$ Institute of Pathology, University Medical Centre Hamburg-Eppendorf, Martinistrasse 52, 20246 Hamburg, Germany. ${ }^{4}$ Department of Gynecology, Albertinen Hospital, Süntelstrasse 11A, 22457 Hamburg, Germany. ${ }^{5}$ Department of Gynecology, DKH Hospital, Hamburg, Hohe Weide 17, 20259 Hamburg, Germany. 'Department of Gynecology, Asklepios Clinic Nord, Tangstedter Landstraße 400, 22417 Hamburg, Germany.}

\section{Authors' contributions}

All authors have made substantive intellectual contributions to the study and given final approval of the final manuscript to be published. LW has designed the study, statistically analyzed and interpreted the data and drafted the manuscript. KK, KM and MI were responsible for data acquisition, carried out the immunoassays and helped to draft the manuscript. MC and EK carried out the $\mathrm{IHC}$ and participated in the design and coordination of the study. JFK carried out statistical analyses, participated in the design of the study and helped to draft the manuscript. $\mathrm{UH}, \mathrm{CL}$ and JS were involved in data acquisition and revised the manuscript critically. FJ and SM participated in the design and coordination of the study and the interpretation of the results. VM helped to draft the manuscript, participated in the design and coordination of the study and the interpretation of the results.

\section{Competing interests}

Volkmar Mueller has received research support by supply of ELISA systems from Oncogene Science at no cost. The other authors declare that they have no competing interests involved with the presented data. This study was funded by internal departmental sources. CAIX immunohistochemistry and ELISA kits were supplied by Oncogene Science without restrictions and participation in study design or data analyses.

Received: 9 September 2010 Accepted: 11 January 2011

Published: 11 January 2011

\section{References}

1. Yeluri S, Madhok B, Prasad KR, Quirke P, Jayne DG: Cancer's craving for sugar: an opportunity for clinical exploitation. J Cancer Res Clin Oncol 2009, 135(7):867-877.

2. Fang JS, Gillies RD, Gatenby RA: Adaptation to hypoxia and acidosis in carcinogenesis and tumor progression. Semin Cancer Biol 2008, 18(5):330-337.

3. Potter $C P$, Harris AL: Diagnostic, prognostic and therapeutic implications of carbonic anhydrases in cancer. Br J Cancer 2003, 89(1):2-7.

4. Winum JY, Poulsen SA, Supuran CT: Therapeutic applications of glycosidic carbonic anhydrase inhibitors. Med Res Rev 2009, 29(3):419-435.

5. Potter C, Harris AL: Hypoxia inducible carbonic anhydrase IX, marker of tumour hypoxia, survival pathway and therapy target. Cell Cycle 2004, 3(2):164-167.

6. Robertson N, Potter C, Harris AL: Role of carbonic anhydrase IX in human tumor cell growth, survival, and invasion. Cancer Res 2004, 64(17):6160-6165.

7. Zavada J, Zavadova Z, Pastorekova S, Ciampor F, Pastorek J, Zelnik V: Expression of MaTu-MN protein in human tumor cultures and in clinical specimens. Int J Cancer 1993, 54(2):268-274.

8. Kaluz S, Kaluzova M, Liao SY, Lerman M, Stanbridge EJ: Transcriptional control of the tumor- and hypoxia-marker carbonic anhydrase 9: A one transcription factor (HIF-1) show? Biochim Biophys Acta 2009, 1795(2):162-172.

9. Ivanov S, Liao SY, Ivanova A, Danilkovitch-Miagkova A, Tarasova N, Weirich G, Merrill MJ, Proescholdt MA, Oldfield EH, Lee J, et al: Expression of hypoxia-inducible cell-surface transmembrane carbonic anhydrases in human cancer. Am J Pathol 2001, 158(3):905-919.

10. Wykoff CC, Beasley NJ, Watson PH, Turner KJ, Pastorek J, Sibtain A Wilson GD, Turley $H$, Talks KL, Maxwell PH, et al: Hypoxia-inducible expression of tumor-associated carbonic anhydrases. Cancer Res 2000, 60(24):7075-7083.

11. Hussain SA, Ganesan R, Reynolds G, Gross L, Stevens A, Pastorek J, Murray PG, Perunovic B, Anwar MS, Billingham L, et al: Hypoxia-regulated carbonic anhydrase IX expression is associated with poor survival in patients with invasive breast cancer. Br J Cancer 2007, 96(1):104-109.

12. Klatte T, Seligson DB, Rao JY, Yu H, de Martino M, Kawaoka K, Wong SG, Belldegrun AS, Pantuck AJ: Carbonic anhydrase IX in bladder cancer: a diagnostic, prognostic, and therapeutic molecular marker. Cancer 2009, 115(7):1448-1458.

13. Loncaster JA, Harris AL, Davidson SE, Logue JP, Hunter RD, Wycoff CC, Pastorek J, Ratcliffe PJ, Stratford IJ, West CM: Carbonic anhydrase (CA IX) expression, a potential new intrinsic marker of hypoxia: correlations with tumor oxygen measurements and prognosis in locally advanced carcinoma of the cervix. Cancer Res 2001, 61(17):6394-6399.

14. Swinson DE, Jones JL, Richardson D, Wykoff C, Turley H, Pastorek J, Taub N, Harris AL, O'Byrne KJ: Carbonic anhydrase IX expression, a novel surrogate marker of tumor hypoxia, is associated with a poor prognosis in non-small-cell lung cancer. J Clin Oncol 2003, 21(3):473-482.

15. Wilex: Phase III ARISER Study (Adjuvant RENCAREX ${ }^{\circledR}$ Immunotherapy Phase III trial to Study Efficacy in non-metastatic RCC). [http://www.wilex. de/R\&D/RENCAREX_Phaselll.htm].

16. Zavada J, Zavadova Z, Zat'ovicova M, Hyrsl L, Kawaciuk I: Soluble form of carbonic anhydrase IX (CA IX) in the serum and urine of renal carcinoma patients. Br J Cancer 2003, 89(6):1067-1071.

17. Woelber L, Mueller V, Eulenburg C, Schwarz J, Carney W, Jaenicke F, MildeLangosch K, Mahner S: Serum carbonic anhydrase IX during first-line therapy of ovarian cancer. Gynecol Oncol 2010, 117:183-188.

18. Li G, Feng G, Gentil-Perret A, Genin C, Tostain J: Serum carbonic anhydrase 9 level is associated with postoperative recurrence of conventional renal cell cancer. J Urol 2008, 180(2):510-513, discussion 513514.

19. Kock L, Mahner S, Choschzick M, Eulenburg C, Milde-Langosch K, Schwarz J, Jaenicke F, Müller V, Woelber L: Serum carbonic anhydrase IX (CAIX) and its prognostic relevance in vulvar cancer. Int J of Gynecol Cancer. 
20. Ferlay J, Shin HR, Bray F, Forman D, Mathers C, Parkin DM: Estimates of worldwide burden of cancer in 2008: GLOBOCAN 2008. Int J Cancer 2010.

21. Burger RA, Monk BJ, Kurosaki T, Anton-Culver H, Vasilev SA, Berman ML, Wilczynski SP: Human papillomavirus type 18: association with poor prognosis in early stage cervical cancer. J Natl Cancer Inst 1996, 88(19):1361-1368.

22. Delgado G, Bundy B, Zaino R, Sevin BU, Creasman WT, Major F: Prospective surgical-pathological study of disease-free interval in patients with stage IB squamous cell carcinoma of the cervix: a Gynecologic Oncology Group study. Gynecol Oncol 1990, 38(3):352-357.

23. Herr D, Konig J, Heilmann V, Koretz K, Kreienberg R, Kurzeder C: Prognostic impact of satellite-lymphovascular space involvement in early-stage cervical cancer. Ann Surg Oncol 2009, 16(1):128-132.

24. de Bruijn HW, Duk JM, van der Zee AG, Pras E, Willemse PH, Boonstra H, Hollema H, Mourits MJ, de Vries EG, Aalders JG: The clinical value of squamous cell carcinoma antigen in cancer of the uterine cervix. Tumour Biol 1998, 19(6):505-516.

25. Duk JM, de Bruijn HW, Groenier KH, Hollema H, ten Hoor KA, Krans M, Aalders JG: Cancer of the uterine cervix: sensitivity and specificity of serum squamous cell carcinoma antigen determinations. Gynecol Oncol 1990, 39(2):186-194.

26. Bolger BS, Dabbas M, Lopes A, Monaghan JM: Prognostic value of preoperative squamous cell carcinoma antigen level in patients surgically treated for cervical carcinoma. Gynecol Oncol 1997, 65(2):309-313.

27. Kirkpatrick JP, Rabbani ZN, Bentley RC, Hardee ME, Karol S, Meyer J, Oosterwijk E, Havrilesky L, Secord AA, Vujaskovic Z, et al: Elevated CAIX Expression is Associated with an Increased Risk of Distant Failure in Early-Stage Cervical Cancer. Biomark Insights 2008, 3:45-55.

28. Lee S, Shin HJ, Han IO, Hong EK, Park SY, Roh JW, Shin KH, Kim TH, Kim JY: Tumor carbonic anhydrase 9 expression is associated with the presence of lymph node metastases in uterine cervical cancer. Cancer Sci 2007, 98(3):329-333.

29. Liao SY, Darcy KM, Randall LM, Tian C, Monk BJ, Burger RA, Fruehauf JP, Peters WA, Stock RJ, Stanbridge EJ: Prognostic relevance of carbonic anhydrase-IX in high-risk, early-stage cervical cancer: a Gynecologic Oncology Group study. Gynecol Oncol 2010, 116(3):452-458.

30. Sobin LH, Wittekind C: UICC TNM classification of malignant tumors. New York. John Wiley \& Sons; 62002.

31. German Society for Obstetrics and Gynecology: Interdisziplinäre S 2-Leitlinie für die Diagnostik und Therapie des Zervixkarzinoms. [http://www.ago-online.org/_download/unprotected/ s2_leitlinie_cx_ca_240104.pdf].

32. Remmele W, Stegner HE: Recommendation for uniform definition of an immunoreactive score (IRS) for immunohistochemical estrogen receptor detection (ER-ICA) in breast cancer tissue. Pathologe 1987, 8(3):138-140.

33. R-Development-Core-Team: R: A language and environment for statistical computing. R Foundation for Statistical Computing. Vienna, Austria 2010 [http://www.R-project.org], ISBN 3-900051-07-0.

34. Choschzick M, Woelber L, Hess S, Eulenburg C, Schwarz J, Simon R, Mahner S, Jaenicke F, Mueller V: Overexpression of carbonic anhydrase IX (CAIX) in vulvar cancer is associated with tumor progression and development of locoregional lymph node metastases. Virchows Arch 2010, 456:483-490.

35. Korkeila E, Talvinen K, Jaakkola PM, Minn H, Syrjanen K, Sundstrom J, Pyrhonen S: Expression of carbonic anhydrase IX suggests poor outcome in rectal cancer. Br J Cancer 2009, 100(6):874-880.

36. Schmitt A, Barth TF, Beyer E, Borchert F, Rojewski M, Chen J, Guillaume P, Gronau S, Greiner J, Moller P, et al: The tumor antigens RHAMM and G250/CAIX are expressed in head and neck squamous cell carcinomas and elicit specific CD8+ T cell responses. Int J Oncol 2009, 34(3):629-639.

37. Svastova E, Hulikova A, Rafajova M, Zat'ovicova M, Gibadulinova A, Casini A, Cecchi A, Scozzafava A, Supuran CT, Pastorek J, et al: Hypoxia activates the capacity of tumor-associated carbonic anhydrase IX to acidify extracellular pH. FEBS Lett 2004, 577(3):439-445.

38. Swietach P, Patiar S, Supuran CT, Harris AL, Vaughan-Jones RD: The role of carbonic anhydrase 9 in regulating extracellular and intracellular $\mathrm{pH}$ in 3-D tumor-cell growths. J Biol Chem 2009, 284:20299-20310.

39. Carney WP: Circulating oncoproteins HER2/neu, EGFR and CAIX (MN) as novel cancer biomarkers. Expert Rev Mol Diagn 2007, 7(3):309-319.
40. Zhou GX, Ireland J, Rayman P, Finke J, Zhou M: Quantification of carbonic anhydrase IX expression in serum and tissue of renal cell carcinoma patients using enzyme-linked immunosorbent assay: prognostic and diagnostic potentials. Urology 2010, 75(2):257-261.

41. Hyrsl L, Zavada J, Zavadova Z, Kawaciuk I, Vesely S, Skapa P: Soluble form of carbonic anhydrase IX (CAIX) in transitional cell carcinoma of urinary tract. Neoplasma 2009, 56(4):298-302

\section{Pre-publication history}

The pre-publication history for this paper can be accessed here: http://www.biomedcentral.com/1471-2407/11/12/prepub

doi:10.1186/1471-2407-11-12

Cite this article as: Woelber et al:: Carbonic anhydrase IX in tumor tissue and sera of patients with primary cervical cancer. BMC Cancer 2011 11:12.

\section{Submit your next manuscript to BioMed Central and take full advantage of:}

- Convenient online submission

- Thorough peer review

- No space constraints or color figure charges

- Immediate publication on acceptance

- Inclusion in PubMed, CAS, Scopus and Google Scholar

- Research which is freely available for redistribution

Submit your manuscript at www.biomedcentral.com/submit
C) Biomed Central 